\title{
ANÁLISE DO CONTRA-ATAQUE NO FUTSAL FEMININO DE ALTO RENDIMENTO
}

João Paulo Shyodi Fukudo, Universidade Estadual de Londrina - UEL, Londrina, Paraná - Brasil

Loani Landin Istchuck, Universidade Estadual de Londrina - UEL, Londrina, Paraná Brasil

Wilton Carlos de Santana, Universidade Estadual de Londrina - UEL, Londrina, Paraná - Brasil

\section{RESUMO}

O objetivo deste estudo é analisar o contra-ataque em jogos de futsal feminino de alto rendimento. Para tanto, é preciso qualificar seu desenvolvimento, descrever, analisar sua frequência e aplicar o método descritivo observacional. A amostra foi de 86 $(17,20 \pm 6,94)$ ações, retiradas de cinco jogos entre as quatro equipes mais bem classificadas da $18^{\mathrm{a}}$ Taça Brasil de Clubes. Os principais resultados indicam seis tipos de contra-ataque, sendo os mais frequentes os realizados com a troca de passes entre as jogadoras, inclusive, com a participação da goleira. Conclui-se que o contra-ataque é incidente em jogos de futsal feminino, que se desenvolve de formas distintas, com uma predominância de ações técnico-táticas coletivas. Os achados do estudo, ao retratar a realidade competitiva, contribuem para que os técnicos da modalidade modelem o treino desse momento do jogo.

Palavras-Chave: Futebol; Feminino; Atletas.

\section{ANALYSIS OF COUNTERATTACK IN FUTSAL WOMEN'S HIGH PERFORMANCE}

\begin{abstract}
The purpose of this study was to analyze the counterattack plays during female futsal high-level matches. In this sense, we characterized the development of the counterattack, described it and analyzed its frequency. We applied an observational and descriptive method to analyze 86 counterattack actions during five matches $(17.20 \pm$ 6.94 counterattacks per match) among the top four teams of the $18^{\text {th }}$ Brazilian Championship. The main results indicated six types of counterattacks, including the plays with sequence of passes which involved the participation of the goalkeeper as the most frequent. The results allowed concluding that counterattack is incident throughout female futsal matches, which occurs in different ways and with predominance of collective technical and tactical actions. Once our findings represent the features of the competitive reality, they supply subsidies to coaches for the training modeling of these moments of the match.
\end{abstract}

Key-Words: Footbal; Female; Athletes. 


\section{ANÁLISIS DEL CONTRAATAQUE EN EL FÚTBOL SALA FEMENINO DE ALTO RENDIMIENTO}

\section{RESUMEN}

El objetivo de este estudio fue analizar los juegos de contraataque alto rendimiento futsal. Por lo tanto, era necesario para calificar su desarrollo, describir y analizar su frecuencia. Se utilizó el método descriptivo observacional. La muestra fue de $86(17,20$ $\pm 6,94)$ acciones, tomadas de cinco partidos entre los cuatro equipos clasificados más altos de la 18 a Copa de Brasil Club. Los principales resultados indican seis tipos de contraataque, las más frecuentes a cabo con el intercambio de pases entre los jugadores, incluso con la participación del portero. Llegamos a la conclusión de que el contraataque es juegos incidentes de futsal, que se desarrolla de diferentes maneras, con predominio de la técnica-táctica colectiva. Los hallazgos del estudio, que retratan la realidad competitiva, contribuyen a que los técnicos del modelo deportivo del entrenamiento de ese momento del juego.

Palabras-Clave: Fútbol; Mujer; Atletas. 


\section{INTRODUÇÃO}

Os jogos esportivos coletivos (JEC) são atividades férteis em acontecimentos imprevisíveis, exigindo dos jogadores uma constante atitude tático-estratégica. ${ }^{1}$ Essa atitude é empregada nos momentos ofensivos, defensivos e de transição do jogo, quando os jogadores precisam selecionar soluções adequadas para os problemas complexos do jogo, ${ }^{2}$ o que lhes exige conhecimento específico para atender às demandas situacionais. ${ }^{3}$

Por conseguinte, há uma preocupação dos pesquisadores em colher informações sobre o jogo, em particular acerca dos seus aspectos ofensivos, não apenas porque expressam o objetivo máximo do jogo, que é o de alcançar gols, pontos, mas também porque explicam os procedimentos táticos usados pelas equipes em realidade competitiva. ${ }^{4}$

Uma ferramenta que tem sido muito utilizada para compreender as solicitações técnicotáticas dos JEC é a análise de jogo, entendida como o estudo observacional da atividade competitiva dos jogadores e das equipes. ${ }^{5}$ Pinto e Garganta ${ }^{6}$ entendem que ela teria o potencial de municiar os treinadores a fim de auxiliá-los na preparação do treino e da competição, repercutindo, por consequência, no conhecimento dos jogadores para enfrentarem as exigências competitivas.

O objeto aqui estudado é o contra-ataque, que é um momento de transição ofensiva, caracterizado pela passagem veloz da defesa para o ataque e que pode se originar através da interceptação de um passe, de um desarme, de uma defesa do goleiro ou ainda de uma rápida reposição de bola. ${ }^{7}$ Sampedro $^{8}$ entende que se trata de uma resposta rápida ao ataque adversário que busca impor uma superioridade numérica. Para Santana ${ }^{3}$ sempre que uma equipe entrar na bola e imprimir um sentido vertical ao ataque, em virtude de encontrar uma defesa desequilibrada numérica e/ou posicionalmente, se trata de um contra-ataque.

Alguns estudos no futsal masculino no âmbito do alto rendimento mostram que o contra-ataque tem se configurado como uma situação incidente e favorável para a marcação de tentos. ${ }^{9-11}$ Isso, muito provavelmente, está associado à vantagem numérica e/ou posicional dos atacantes sobre os defensores. ${ }^{12-13}$ Entretanto, pouco se sabe sobre o 
desenvolvimento desse momento do jogo no futsal feminino, modalidade em franca ascensão competitiva no Brasil desde meados dos anos 2000, ${ }^{14}$ quando do advento de campeonatos brasileiros de categorias menores a partir dos anos de 2003 (Sub-20), 2004 (Sub-15) e 2005 (Sub-20) e, sobretudo, pela criação da Liga Futsal Feminina, em 2005.

Diante disso, o objetivo deste estudo é analisar o contra-ataque em jogos de futsal feminino de alto rendimento, qualificando seu desenvolvimento, descrevendo e analisando sua frequência.

\section{MÉTODOS}

Trata-se de um estudo de cunho descritivo observacional de delineamento transversal. ${ }^{15}$ A amostra foi constituída de $86(17,20 \pm 6,94)$ ações, retiradas de cinco jogos entre as quatro equipes mais bem classificadas da $18^{\mathrm{a}}$ Taça Brasil de Clubes, a competição nacional mais tradicional, que reuniu nessa edição 26 equipes na fase classificatória e oito na fase decisiva. A fase final foi realizada em Londrina (PR). A seleção da presente amostra foi do tipo não-probabilístico intencional ${ }^{16}$ e teve como critério o fato de as equipes pertencerem a um grupo de futsalonistas de elite, participantes de uma competição oficial. O estudo recebeu parecer favorável do "Comitê de Ética em Pesquisa Envolvendo Seres Humanos na Universidade Estadual de Londrina/Hospital Regional Norte do Paraná" (Registro CONEP 268). Parecer PF Nº 192/09.

\section{Instrumentos e procedimentos}

A coleta de dados foi feita da observação das imagens vídeo gravadas dos jogos em mídia DVD. O apelo ao meio audiovisual foi escolhido por permitir a visualização repetida e detalhada dos comportamentos tático-técnicos, de modo a diminuir os erros de observação. Os dados foram anotados em formulários específicos elaborados pelos pesquisadores.

\section{Análise estatística}

Foram determinados valores de frequência absoluta $(\mathrm{F})$ e relativa $(\%)$ para os dados obtidos no estudo. 


\section{Qualidade da informação}

Com o objetivo de verificar a consistência das observações dos tipos de contra-ataque e suas respectivas frequências, foi realizada uma prova de reprodutibilidade intraobservador e outra inter-observador, com intervalo de 15 dias. Diante dos dados coletados, foi analisada a percentagem de acordos e desacordos, segundo a fórmula usada por Garganta, ${ }^{17}$ na qual o autor indica como satisfatório o índice de $85 \%$. Registraram-se, respectivamente, os valores de $97,6 \%$ e $95,3 \%$.

\section{RESULTADOS}

$\mathrm{Na}$ Tabela 1 está descrita a qualificação do contra-ataque e os respectivos conceitos técnico-táticos que a suportam. Pode-se observar que o contra-ataque se desenvolve a partir de situações distintas, com a participação das jogadoras de linha, mas também com a contribuição da goleira. Igualmente, nota-se que dois tipos de contra-ataque foram desencadeados a partir da defesa de contra-ataque.

Tabela 1 - Qualificação do contra-ataque no futsal feminino de alto rendimento

\begin{tabular}{|c|c|}
\hline Tipos de contra-ataque & Conceito técnico-tático \\
\hline Individual & A jogadora contra-atacou sem passar a bola \\
\hline Assistido pela linha & $\begin{array}{l}\text { Houve troca de passe entre as jogadoras de } \\
\text { linha no contra-ataque }\end{array}$ \\
\hline Assistido pela goleira após defesa & $\begin{array}{l}\text { A goleira iniciou o contra-ataque após } \\
\text { defender a bola }\end{array}$ \\
\hline Assistido pela goleira de arremesso de meta & $\begin{array}{l}\text { A goleira iniciou o contra-ataque de } \\
\text { arremesso de meta }\end{array}$ \\
\hline Contra do contra-ataque assistido & $\begin{array}{l}\text { A equipe contra-atacada recuperou a bola e } \\
\text { contra-atacou com troca de passe }\end{array}$ \\
\hline Contra do contra-ataque individual & $\begin{array}{l}\text { A equipe contra-atacada recuperou a bola e } \\
\text { contra-atacou sem troca de passe }\end{array}$ \\
\hline
\end{tabular}

Na Tabela 2 são apresentadas as frequências absolutas e relativas dos tipos de contraataque. Na análise desta tabela verifica-se que 59,3\% das ações de contra-ataque exigiram a troca de passes entre as jogadoras. Destas, 51,2\% foram desenvolvidas com troca de passes entre as jogadoras de linha. Observa-se, igualmente, que o contra do contra-ataque representou $11,6 \%$ do total de ações. 
Tabela 2 - Tipos de contra-ataque e suas respectivas frequências em jogos de futsal feminino de alto rendimento

\begin{tabular}{lll}
\hline Tipos de contra-ataque & F & \% \\
\hline Assistido pela linha & 38 & 44,2 \\
Individual & 31 & 36 \\
Contra do contra-ataque assistido & 6 & 7 \\
Assistido pela goleira após defesa & 6 & 7 \\
Contra do contra-ataque individual & 4 & 4,6 \\
Assistido pela goleira de arremesso de meta & 1 & 1,2 \\
\hline Total & 86 & 100 \\
\hline
\end{tabular}

\section{DISCUSSÃO}

O contra-ataque se constitui num dos momentos ou fases do jogo de futsal, respondendo pela transição ofensiva. Compreender sua demanda competitiva, mediante a análise de jogo, tem o potencial de municiar os treinadores da modalidade para uma melhor gestão do treino e da competição, o que repercute no conhecimento dos jogadores quando do enfrentamento dessa situação.

Neste estudo, procurou-se analisar o contra-ataque em jogos de futsal feminino de alto rendimento, qualificando, num primeiro momento, seu desenvolvimento, ou seja, como ocorre nos jogos. Verificou-se na realidade competitiva dessa modalidade, que além das ações de cunho individual, assistido e com a participação da goleira, que retratam em geral as tipologias do contra-ataque reportadas pela literatura, ${ }^{11,18-19}$ a incidência de $11,6 \%$ do total de contra-ataques desencadeados a partir da defesa de contra-ataque. Por isso, houve a necessidade de incluir a categoria "contra do contra-ataque", tanto assistido como individual, como demonstram a Tabela 1 e 2 .

Além de qualificar seu desenvolvimento, procurou-se no presente estudo descrever e analisar a frequência dos diferentes tipos de contra-ataque. A predominância de contraataques do tipo assistido sobre os de cunho individual demonstrada na Tabela 1 converge com achados de Marchi et al., ${ }^{10}$ que ao analisarem o contra-ataque em 20 jogos da Liga Futsal 2009, constataram que 63,8 \% foram do tipo indireto, isto é, que exigiram troca de passes entre os jogadores, e 35,8\% foram do tipo direto, o qual não se exige a troca de passes. Por outro lado, é superior ao achado de Santana e Garcia, ${ }^{11}$ que 
ao analisarem 28 jogos da Liga Futsal 2003, reportaram que 28,2\% foram do tipo assistido e $71,8 \%$ do tipo individual.

É plausível que a predominância de contra-ataques do tipo assistido sobre os de tipo individual dos estudos mais recentes se justifique pelo aumento das dimensões da quadra em competições no âmbito nacional, que a partir do ano de 2007 exigiu medidas mínimas de 36x18metros ${ }^{20}$ contra as dimensões mínimas de 30x17 metros dos anos anteriores. Por conseguinte, em hipótese, o maior espaço de jogo dificultaria a condução individual da bola em situação de contra-ataque e, por oposição, exigiria a troca de passes entre os atletas.

A frequência de $8,2 \%$ de contra-ataques iniciados pela goleira deste estudo converge com a encontrada por Cruz, ${ }^{21}$ que ao analisar o desenvolvimento do contra-ataque em quatro jogos da VI Copa do Mundo de Futsal, verificou que 10\% se originaram dessa situação. Igualmente, reforça o achado de Santana e Garcia, ${ }^{11}$ que reportaram 9,79\% das ações de contra-ataque iniciadas por esse jogador.

Pode causar estranheza ações de contra-ataque a partir do arremesso de meta, haja vista que os defensores, pelo menos em teoria, deveriam se encontrar bem posicionados, o que dificultaria o ataque veloz. Entretanto, isso se explica, sobretudo, pela interferência contextual da chamada "quadra rápida", isto é, aquela que comporta parede muito próxima atrás da baliza, a qual, quando da ocorrência de uma finalização malsucedida, "devolve" rapidamente a bola para as mãos do goleiro. ${ }^{3}$ Isso serve de alerta para as equipes que terminam seus ataques com uma finalização para fora do gol em quadras com essas características. Nestas, os atacantes deveriam se preocupar em se converter rapidamente em defensores de um possível contra-ataque.

\section{CONCLUSÃO}

A análise do contra-ataque em jogos de futsal feminino de alto rendimento permitiu qualificar seis ações distintas desse tipo de situação. Encontrou-se uma predominância de contra-ataques que exigiram a troca de passe entre as jogadoras de linha sobre os que foram desenvolvidos de forma individual. Foram menos incidentes o contra do contraataque e aqueles iniciados pela goleira.

Conexões: revista da Faculdade de Educação Física da UNICAMP, Campinas, v. 11, n. 4, p. 90-199, out./dez. 2013. ISSN: 1983-9030 
Este estudo pretende contribuir com a organização metodológica de treinos de contraataque. Salienta-se que é preciso que sejam produzidos mais materiais envolvendo estudos das variáveis técnico-táticas no futsal feminino, para que as comparações dos achados sejam realizadas dentro da própria modalidade e não com o futsal masculino.

\section{Aplicações práticas}

Introduzir no treinamento do contra-ataque a troca de passe entre as jogadoras e, igualmente, ações que exijam exercitá-lo de forma individual;

Introduzir no treinamento a exercitação do contra do contra-ataque. Desse modo, além da situação ofensiva, se exercitaria a defesa do contra-ataque;

Incluir desenhos metodológicos que exijam a participação da goleira no início do contra-ataque após realizar uma defesa e de arremesso de meta, com a bola voltando rapidamente para as suas mãos.

\section{REFERÊNCIAS}

${ }^{1}$ PAULA, P. F. A.; GRECO, P. J.; SOUZA, P.R.C. Tática e processos cognitivos subjacentes à tomada de decisão nos jogos esportivos coletivos. In: GARCIA, E. S.; LEMOS, K. L. M. Temas atuais V: educação física e esportes. Belo Horizonte: Health, 2000. p. 11-27.

${ }^{2}$ PINHO, S. et al. Método situacional e sua influência no conhecimento tático processual de escolares. Motriz, Rio Claro, v. 16, n. 3, p. 580-590, jul./set. 2010.

\section{${ }^{3}$ SANTANA, W. C. A visão estratégico-tática de técnicos campeões da Liga}

Nacional de Futsal. 2008. 260 f. Tese (Doutorado em Educação Física) - Faculdade de Educação, Universidade Estadual de Campinas, Campinas, 2008.

${ }^{4}$ LAGO, J. et al. El éxito ofensivo en el fútbol de élite. Influencia de los modelos tácticos empleados y de las variables situacionales. Motricidad: european journal of human movement, v. 28, p.145-170, jun. 2012. 
${ }^{5}$ GARGANTA, J. A. análise da performance nos jogos desportivos: revisão acerca da análise de jogo. Revista Portuguesa de Ciências do Desporto, Porto, v.1, n.1, p. 5764, 2001.

${ }^{6}$ PINTO, J.; GARGANTA, J. Contributo da modelação da competição e do treino para a evolução do nível do jogo no futebol. In: OLIVEIRA, J.; TAVARES, F. Estratégia e táctica nos jogos desportivos colectivos. Porto: FCDEFUP, 1996. p. 83-94.

${ }^{7}$ SANTANA, W. C. Futsal: apontamentos pedagógicos na iniciação e na especialização. Campinas: Autores Associados, 2004.

${ }^{8}$ SAMPEDRO, J. Fundamentos de táctica deportiva. Madrid: Gymnos, 1999.

${ }^{9}$ FUKUDA, J. P.; SANTANA, W. C. Análise dos gols em jogos da Liga Futsal 2011. Revista Brasileira de Futsal e Futebol, São Paulo, v. 4, n. 11, p. 62-66, Jan./Abr. 2012.

${ }^{10}$ MARCHI, R. et al. Incidência de gols resultantes contra-ataques de equipes de futsal. Conexões, Campinas, v. 8, n. 3, p. 16-22, 2010.

${ }^{11}$ SANTANA, W. C.; GARCIA, O. B. A incidência do contra-ataque em jogos de futsal de alto rendimento. Pensar a Prática, Goiânia, v. 10, n. 1, p. 153-162, 2007.

${ }^{12}$ ANDRADE JUNIOR, J. R. O jogo de futsal: técnico e tático na teoria e na prática. Curitiba: Expoente, 1999.

${ }^{13}$ CHAVES-CHAVES, J.; RAMÍREZ-AMOR, J. Táctica y estratégia em fútbol sala: situaciones de ataque y defensa. Barcelona: Hispano Europea, 1998.

${ }^{14}$ SANTANA, W. C,; REIS, H. H. B. Futsal feminino: perfil e implicações pedagógicas. Revista Brasileira de Ciência e Movimento, Brasília, v. 11, n. 4, p. 45-50, out./dez. 2003. 
${ }^{15}$ GAYA, A. Desenhos metodológicos V: delineamentos do tipo ex post facto. In: GAYA, A. (Org.) Ciências do movimento humano: introdução à metodologia da pesquisa. Porto Alegre: Artmed, 2008. p. 151-172.

${ }^{16}$ CASTRO, J. M.; MESQUITA, I. Estudo das implicações do espaço ofensivo nas características do ataque no voleibol masculino de elite. Revista Portuguesa de Ciências do Desporto, Porto, v. 8, n.1, p. 114-125, 2008.

${ }^{17}$ GARGAnTA, J. Modelação táctica do jogo de futebol. 1997. 292 f. Tese (Doutorado em Ciências do Desporto) - Faculdade de Ciências do Desporto e de Educação Física da Universidade do Porto, Porto, 1997.

${ }^{18}$ BELLO JUNIOR, N. A ciência do esporte aplicada ao futsal. Rio de Janeiro: Sprint, 1998.

${ }^{19}$ VOSER, R. Futsal: princípios técnicos e táticos. Rio de Janeiro: Sprint, 2001.

${ }^{20}$ BARBIERI, F. A. As regras do futsal e as constantes alterações. In: BARBIERI, F. A. Futsal: conhecimentos teórico-práticos para o ensino e o treinamento. Jundiaí: Fontoura, 2009, p. 25-32.

${ }^{21}$ CRUZ, L. M. F. Configuração do contra-ataque em jogos entre semifinalistas da VI Copa do Mundo de Futsal. 2009. 39 f. Trabalho de Conclusão de Curso (Bacharelado em Esporte) - Universidade Estadual de Londrina, Londrina, 2009.

Recebido em: 15 dez. 2012 Aceito em: 09 out. 2013 Contato: Wilton Carlos de Santana wilton@uel.br 